\title{
Clinical and Microbiological Characteristics of Infective Endocarditis at a Cardiac Center in Saudi Arabia
}

\author{
Mazin Barry ${ }^{1}$ - Syed Abdul Bari ${ }^{2} \cdot$ Muhammad Yasin Akhtar $^{2} \cdot$ Faizah Al Nahdi $^{2} \cdot$ Richilda Erlandez $^{2}$. \\ Abdullah Al Khushail ${ }^{3}$. Yahya Al Hebaishi ${ }^{3}$
}

Received: 27 August 2021 / Accepted: 21 October 2021 / Published online: 4 November 2021

(c) The Author(s) 2021

\begin{abstract}
Background Infective endocarditis (IE) is a serious disease with complex pathology and significant mortality. Little information is known regarding clinical and microbiological characteristics in Saudi Arabia. This study surveyed these characteristics at a Cardiac Center in Riyadh, Saudi Arabia over a period of 5 years.

Methods This retrospective study was done on all infective endocarditis (IE) patients admitted to Prince Sultan Cardiac Center between January 1, 2015, and December 31, 2019. Clinical characteristics, microbiological results, management, and outcomes were assessed.

Result A total of 340 cases of infective endocarditis were identified over the study period.

Most patients (64\%) were 50 years old or above, and 67\% were males. Fever was the most common clinical presentation, and a murmur was audible in a fifth of patients. Blood cultures were positive in 177 (52\%) cases. The most common organisms were Staphylococcus aureus, coagulase negative Staphylococcus and viridans group Streptococcus. Most common microbiological organisms causing native valve endocarditis were viridans group Streptococcus (32\%) followed by methicillin-susceptible Staphylococcus aureus (21\%), and for prosthetic valve endocarditis they were coagulase negative Staphylococcus (32\%) followed by methicillin-susceptible Staphylococcus aureus (23\%), the most common causes of culture negative endocarditis were Q-fever and brucellosis. Predisposing cardiac conditions were present in 127 (37\%) patients, most commonly rheumatic heart disease and congenital heart disease. Surgical intervention was done in $26 \%$ of cases, with an overall in-hospital mortality rate of $6.76 \%$.

Conclusion We demonstrate the epidemiological, clinical, and microbiological profile of infective endocarditis in a tertiary care cardiac center in Saudi Arabia. It gives information concerning the prevalence of responsible organisms. This information will be helpful in assessing patients with suspected IE and in planning management of cases knowing the relative frequency of types of microorganisms encountered.
\end{abstract}

Keywords Infective endocarditis $\cdot$ Rheumatic heart disease $\cdot$ Congenital heart disease $\cdot$ Staphylococcus

Mazin Barry

mbarry@ksu.edu.sa

Syed Abdul Bari

drsabari7may@gmail.com

Muhammad Yasin Akhtar

makhtar@pscc.med.sa

Faizah Al Nahdi

f.alnahdi@pscc.med.sa

Richilda Erlandez

rerlandez@pscc.med.sa

Abdullah Al Khushail

aalkhushail@pscc.med.sa
Yahya Al Hebaishi

yalhebaishi@pscc.med.sa

1 Division of Infectious Diseases, Department of Internal Medicine, College of Medicine, King Saud University, PO Box 2925, Riyadh 11461, Saudi Arabia

2 Department of Infection Control, Prince Sultan Cardiac Center, Riyadh, Saudi Arabia

3 Department of Adult Cardiology, Prince Sultan Cardiac Center, Riyadh, Saudi Arabia 


$\begin{array}{ll}\text { Abbreviations } \\ \text { IE } & \text { Infective endocarditis } \\ \text { KSA } & \text { Kingdom of Saudi Arabia } \\ \text { PSCC } & \text { Prince Sultan Cardiac Center } \\ \text { CBC } & \text { Complete blood count } \\ \text { DVT } & \text { Deep vein thrombosis } \\ \text { MSSA } & \text { Methicillin Sensitive Staphylococcus Aureus } \\ \text { MRSA } & \text { Methicillin resistant Staphylococcus Aureus } \\ \text { CONS } & \text { Coagulase negative Staphylococcus } \\ \text { TTE } & \text { Transthoracic echocardiography } \\ \text { TEE } & \text { Transesophageal echocardiography } \\ \text { VRE } & \text { Vancomycin resistant Enterococcus } \\ \text { MDR } & \text { Multidrug resistant organism } \\ \text { XDR } & \text { Extensively drug resistant organism }\end{array}$

\section{Introduction}

Infective endocarditis (IE) remains a potentially lethal disease with varied clinical presentations and significantly changing epidemiology. It may be classified as acute, subacute, or chronic depending on the course of infection, however, it is more commonly classified according to the type of valve involved into native or prosthetic valve endocarditis which influences the causative pathogens. Recent reports from developed countries have focused on changes in the epidemiology, microbiology, and clinical features of IE [1] as well as major advances in diagnosis and management of this clinical disease [1,2]. The incidence of IE is estimated to be $0.16-5.4$ cases per 1000 hospital admissions. Most patients are aged between 30 and 60 years old with a male predominance [1].

Since Osler's first description in 1885 , the clinical features of IE have changed due to decrease in rheumatic heart disease, an increasing percentage of elderly people, comorbidities, nosocomial exposures, prosthetic valves, intra-cardiac devices, intravenous drug use, and hemodialysis [3]. A microbiological shift from streptococci spp. to staphylococci spp. as the more frequent causative pathogen has been significantly noted [4]. With increasing rates of multidrug resistant organisms including Methicillin-resistant Staphylococcus aureus [5]. Due to disease complexity, the diagnosis of IE is standardized by the Duke-Li classification which combines two major criteria related to microbiology and imaging with five minor criteria. In cases of prosthetic valve IE the use of radiolabeled leukocyte scintigraphy or positron emission tomography (PET) can further enhance the diagnosis [6], in addition to the use of polymerase chain reaction (PCR) assays for blood culture-negative IE [7]. Despite the disease's well described clinical features, diagnosis and treatment can still be challenging with an overall mortality reaching up to $20 \%$, as IE is a complex disease which may vary depending on the first organ involved, underlying cardiac disease, causative microorganism, presence or absence of complications, and the patient's underlying characteristics [5].

Data regarding clinical and microbiological features of IE in the Kingdom of Saudi Arabia (KSA) are limited, as one report estimated the rate of definitive IE in KSA to be about 15 cases per 100,000 admissions/discharges [8], while internationally the estimated incidence is $3-10$ cases per 100,000 per year [9]. The aim of this retrospective case series was to describe the clinical, microbiological and echocardiographic characteristics of patients with IE over a five-year period at Prince Sultan Cardiac Center (PSCC), a governmental hospital in the Central region of KSA, located in the capital city Riyadh. The hospital is comprised of 220 hospital beds and is the largest cardiac center in the country, with comprehensive cardiac services, serving referred patients from all over KSA.

\section{Materials and Methods}

\subsection{Study Design}

A systematic retrospective review of medical records of all patients admitted to PSCC from January 1, 2015, to December 31, 2019, with the diagnosis of definite infective endocarditis according to the modified Duke criteria was included.

The study was reviewed and approved by the center's ethics committee board with research file number R20012.

\subsection{Demographic and Clinical Data}

Data from medical records were collected on the following: demographic variables: age, gender, clinical presentation data including symptoms and signs were noted. Transthoracic and transesophageal echocardiography were performed, and data collected regarding, type of valve, type of underlying cardiac abnormalities and any other abnormalities. Rate of surgical intervention as well as variable complications including congestive heart failure, systemic embolization, stroke, and renal impairment were reviewed and recorded.

\subsection{Microbiological Data}

Data were collected on all blood culture results, type of microorganism and antibiotics susceptibility. The microbiology laboratory used the standardized methods to identify microorganisms and the antimicrobial susceptibility. Blood culture-negative endocarditis had additional testing which include fungal cultures, serology for Coxiella burnetti using enzyme Immunoassay serology by Bioscientia ${ }^{\circledR}$ Institute 
of medical diagnostics Germany and Indirect Immunofluorescence test by Mayo ${ }^{\circledR}$ clinic USA, as well as Brucella melitensis, Brucella abortus and Bartonella hensale serologies by enzyme linked immunoassay.

Statistical analysis by descriptive statistics: (using means and standard deviations for continuous variables and frequencies for qualitative variables) using SPSS software package.

\section{Results}

A total of 345 patients were admitted to PSCC with the diagnosis of infective endocarditis, of which 340 fulfilled modified Duke's Criteria, of those 228 cases (67\%) were male and 112 cases $(33 \%)$ were female. Most patients were between 51 and 60 years with a range of $18-99$ years. Mean age was 48 years. Age distribution is listed in (Table 1).

\subsection{Clinical Manifestations}

Fever was the most common clinical finding in 320 (94\%) of patients, fatigue and sweating in $58(17 \%)$ patients, dyspnea was present in 14 patients $(4.11 \%)$, an audible murmur was present in 61 cases (18\%). Clinical findings are listed in (Table 2).

\subsection{Predisposing Factors}

Risk factors and underlying heart disease in patients with IE are shown in (Table 2). Of the 340 patients, 109 (32\%) had prosthetic valve endocarditis and $111(32.6 \%)$ patients had native valve endocarditis. 51(15\%) patients had rheumatic heart disease with valvular lesions and $32(9.4 \%)$ patients
Table 2 Clinical findings and risk factors of IE patients

\begin{tabular}{lll}
\hline Symptoms/Signs & No. of patients & $\%$ \\
\hline Fever with murmur & 61 & 18 \\
Shortness of Breath & 14 & 4.1 \\
Stroke & 04 & 1.2 \\
Splenomegaly & 05 & 1.5 \\
Hepatosplenomegaly & 14 & 4.1 \\
Others-DVT & 01 & - \\
Prosthetic valve & 109 & 32 \\
Rheumatic heart disease & 51 & 15 \\
Congenital heart disease & 32 & 9.4 \\
Intra-cardiac device & 28 & 8.2 \\
Hemodialysis line & 12 & 3.5 \\
Nosocomial & 4 & 1.1 \\
Dental procedures & 7 & 2.0 \\
\hline
\end{tabular}

Deep vein thrombosis

Fisher exact test

$P<0.005$

had congenital heart disease ( 5 cases with ventricular septal defect, 10 cases with Tetralogy of Fallot, 1 case with atrial septal defect).

\subsection{Microbiology}

Blood cultures were incubated in BD BACTEC ${ }^{\mathrm{TM}}$ system, identification and susceptibility were performed using VITEK® 2 microbial identification system. A total of 177 patients $(52.05 \%)$ had positive blood cultures (Table 3). The most common isolated organisms were Staphylococcus spp. which was found in 80 patients of which 53 were due to Staphylococcus aureus with 36 being methicillin-susceptible

Table 1 Age and gender distribution

\begin{tabular}{lll}
\hline Age (years) & No. of patients $(N=340)$ & $\%$ \\
\hline $18-20$ & 34 & 10 \\
$21-30$ & 43 & 12.64 \\
$31-40$ & 47 & 13.82 \\
$41-50$ & 60 & 17.64 \\
$51-60$ & 61 & 17.94 \\
$61-70$ & 54 & 15.88 \\
$>70$ & 41 & 12.05 \\
Mean \pm SD of the Age group $48.09 \pm 18.94$ & & $\%$ \\
\hline Gender & No. of the patients $(N=340)$ & 67.05 \\
\hline Male & 228 & 32.94 \\
Female & 112 & \\
\hline
\end{tabular}

*Fisher exact test

$P=0.005$ 
Table 3 Total number of blood cultures $(N=340)$

\begin{tabular}{lll}
\hline Culture & Number & $\%$ \\
\hline Culture positive & 177 & 52 \\
\hline Bacterial culture positive No=172 $(97.1 \%)$ & & 144 \\
\hline Gram positive bacteria & 28 & 83.72 \\
Gram negative bacteria & 05 & 16.27 \\
Fungal (Candida Spp.) & 2.82 \\
\hline
\end{tabular}

*Fisher exact test

$P<0.005$

Staphylococcus aureus (MSSA) and 17 methicillin-resistant Staphylococcus aureus (MRSA), while 27 were due to coagulase-negative Staphylococcus. The second most common isolated organisms were Streptococcus spp. In 37 patients, Enterococcus spp. in 27 patients. For blood culture-negative endocarditis, the most common cause was Q-fever in 19 of the 32 patients with congenital heart disease, followed by brucellosis, these and other microbiological etiological agents are outlined in (Table 4).

Type of positive isolates in native and prosthetic valves are shown in (Table 5). Of the Total 177 isolates from 340 patients, 172 were bacterial and 5 were fungal isolates, out

Table 4 Microbiological agents

Gram positive organisms (No $=144)$

\begin{tabular}{|c|c|c|c|}
\hline Organism & Staphylococcus spp. $80(55.5 \%)$ & Enterococcus spp. $27(18.75 \%)$ & Streptococcus spp. 37 (25.\%) \\
\hline & Methicillin-susceptible S. aureus (MSSA)- 36(45\%) & Enterococcus faecalis- 22 (81.5\%) & Streptococcus. viridans 29 (78.4\%) \\
\hline & Methicillin resistant S. aureus (MRSA)-17(21\%) & $\begin{array}{l}\text { Vancomycin resistant Enterococcus } \\
\text { (VRE)- } 5(18.5 \%)\end{array}$ & Streptococcus Salivarus 2 (5\%) \\
\hline & Coagulase negative Staphylococcus (CONS)-27(34\%) & & Streptococcus milleri 2 (5.4\%) \\
\hline & & & Streptococcus bovis 1 (3\%) \\
\hline & & & Streptococcus. angiosus 1 (3\%) \\
\hline Gram nega & ve organisms $(\mathrm{No}=28)$ & & \\
\hline Name of th & organism & No. of isolates \& \% & Drug resistance \\
\hline Klebsiella & neumoniae & $9(32.1 \%)$ & $\begin{array}{l}\text { MDR } 5(55.5 \%) \\
\text { XDR } 1(11.1 \%)\end{array}$ \\
\hline Enterobact & r cloacae & $2(7.1 \%)$ & - \\
\hline Burkholde & a cepacia & $1(3.5 \%)$ & - \\
\hline Stenotroph & monas maltophilia & $1(3.5 \%)$ & - \\
\hline Ochrobact & ium anthropi & $1(3.5 \%)$ & - \\
\hline Aggregatib & cter aphrophilus & $1(3.5 \%)$ & - \\
\hline Brucella $m$ & litensis & $12(42.8 \%)$ & - \\
\hline Niesseria & ongate & $1(3.5 \%)$ & \\
\hline Culture ne & tive endocarditis (Serology Positive) & & \\
\hline Organism & & Positive $(N=30)$ & $\%$ \\
\hline Coxiella $b$ & netii & 19 & 63.3 \\
\hline Brucella s & & 9 & 30 \\
\hline Chlamydia & neumoniae & 1 & 3.3 \\
\hline Bartonella & enselae & 1 & 3.3 \\
\hline
\end{tabular}

$M D R$ multidrug resistant, $X D R$ extensively drug resistant

*Fisher Exact test

$P<0.005$ 
Table 5 Total positive isolates in NATIVE and prosthetic valves-158 (89.2\%)

\begin{tabular}{|c|c|c|c|}
\hline Native valve endocarditis & $111(32.6 \%)$ & Prosthetic valve endocarditis & $109(32 \%)$ \\
\hline \multicolumn{2}{|l|}{ Bacterial isolate in native valve endocarditis } & \multicolumn{2}{|l|}{ Bacterial isolate in prosthetic valve endocarditis } \\
\hline Total isolate & $70(44.3 \%)$ & Total isolate & $88(55.7 \%)$ \\
\hline Bacterial & $67(95.7 \%)$ & Bacterial & $87(98.8 \%)$ \\
\hline Fungal & $3(4.3 \%)$ & Fungal & $1(1.2 \%)$ \\
\hline Gram positive organisms & $57(85 \%)$ & Gram positive organisms & $75(86.2 \%)$ \\
\hline \multicolumn{2}{|l|}{ Staphylococcus Species(26) $38.8 \%$} & \multicolumn{2}{|l|}{ Staphylococcus Species (54) 62\% } \\
\hline MSSA & $16(23.8 \%)$ & MSSA & $19(21.8 \%)$ \\
\hline CONS & $5(7.5 \%)$ & CONS & $28(32.1 \%)$ \\
\hline MRSA & $5(7.5 \%)$ & MRSA & $7(8 \%)$ \\
\hline Streptococcus viridans & $18(31.5 \%)$ & Streptococcus viridans & $9(10.3 \%)$ \\
\hline Enterococcus faecalis & $11(19.30 \%)$ & Enterococcus faecalis & $8(9.1 \%)$ \\
\hline Streptococcus anginosus & $1(1.75 \%)$ & Streptococcus salivarus & $1(1.14 \%)$ \\
\hline Streptococcus hominis & $1(1.75 \%)$ & Streptococcus agalactiae & $1(1.14 \%)$ \\
\hline- & & Streptococcus mitis & $1(1.14 \%)$ \\
\hline- & & Streptococcus bovis & $1(1.14 \%)$ \\
\hline Gram negative organisms & $10(15 \%)$ & Gram negative organisms & $12(13.8 \%)$ \\
\hline Klebsiella pneumoniae & $6(60 \%)$ & Klebsiella pneumoniae & $4(33.3 \%)$ \\
\hline Brucella melitensis & $3(30 \%)$ & Brucella melitensis & $3(25 \%)$ \\
\hline \multirow[t]{4}{*}{ Ochrobacterium anthropic } & $1(10 \%)$ & Enterobacter cloacae & $2(16.6 \%)$ \\
\hline & & Aggregatibacter aphrophilus & $1(8.3 \%)$ \\
\hline & & Burkholderia cepacia & $1(8.3 \%)$ \\
\hline & & Nisseria elongatata & $1(8.3 \%)$ \\
\hline Fungal & & Fungal & \\
\hline Candida albicans & $3(4.3 \%)$ & Candida albicans & $1(1.1 \%)$ \\
\hline
\end{tabular}

MSSA Methicillin-susceptible Staphylococcus aureus, MRSA methicillin-resistant Staphylococcus aureus, CONS coagulase-negative Staphylococcus

Fisher exact test

$P<0.005^{*}$

of which 158 (89.27\%) were positive in combined native and prosthetic valves infective endocarditis, the remaining $19(10.73 \%)$ isolates were device or health care associated.

\subsection{Echocardiography}

Echocardiography was performed in all patients by transthoracic echocardiography (TTE), transesophageal echocardiography (TEE) was done in 224 (65.8\%) patients.

The average vegetations size was $+7.5 \mathrm{~mm}$. Vegetations on the mitral valve were detected in $122(36 \%)$ patients, of those moderate to severe mitral regurgitation was detected in $101(82 \%)$ patients. The aortic valve was involved in 79 (23\%) patients, of the latter 51 (64\%) had moderate to severe regurgitation. Severe tricuspid regurgitation in 17 patients (5\%), the pulmonary valve in 14 patients (4\%). Mitral and aortic valve were both affected in 24 patients (7\%), Mitral and tricuspid valves in $13(3.8 \%)$ patients, and pulmonary with tricuspid valves in 1 patient.

\subsection{Treatment, Complications, and Outcome}

All patients received at least two intravenous antibiotics according to culture results, ceftriaxone was the most common antimicrobial used (62\%), followed by vancomycin $(56 \%)$, cefazolin $(29 \%)$, and gentamicin $(18 \%)$. In cases of culture-negative endocarditis, empirical antibiotic therapy was applied.

Complications that required surgical intervention occurred in 89 patients $(26.17 \%)$; the indications for surgery were congestive heart failure in 30 patients $(9 \%)$, mobile vegetation larger than $1.2 \mathrm{~cm}$ in 26 patients (7.6\%), systemic embolization in 18 patients (5\%), stroke in 15 patients (2.2\%). Renal failure requiring renal replacement therapy 
occurred in 67 patients (20\%) The in-hospital mortality rate attributed directly to IE was $6.76 \%$ (23 patients).

\section{Discussion}

Infective endocarditis is still associated with high mortality and complications. Changes have been reported in the epidemiological and microbiological profile of IE over the last 30 years [10]. IE is more commonly seen in older age groups with a predominance of male patients and an increased incidence of acute IE caused by virulent organisms such as Staphylococcus aureus, while Gram-negative organisms are seen in nosocomial and device related infections.

In common with reports from developed countries, our study reveals that the male to female ratio agreed with most case series [11]. While our patient population had a mean age of 48 years, $55 \%$ of patients were aged above 50 years and $12 \%$ of patients were aged above 70 years. In comparison, a study from a hospital in the Eastern region of KSA by Al-Tawfiq et al. on 83 IE patients over a thirteen-year period reported a mean age of 59.7 years [8], while another study from Aseer region by Assiri on 44 patients over a five-year period reported a mean age of 31 years [12]. A study by Zaqout et al. from Qatar, a neighboring country to KSA, examined 57 patients with IE over a three-year period, they reported the mean age to be 51 years [13]. Elsewhere data from the United States has shown that more than $50 \%$ of all IE cases were seen in patients over the age of 60 years, with a steady increase in the mean age of 45.3 years in the 1980 s to 57.2 years in the 2000s [14]. This trend in developed countries is probably due to two factors: the increasing proportion of elderly people in the general population and the decline in the incidence of rheumatic heart disease [15]. In our patient population, second to prosthetic heart valves, rheumatic heart disease was the most common underlying cardiac condition as reported by Andrea et al. [16].

Fever was found to be the most common symptom in our cohort which was reported in more than $90 \%$ of patients which is similar to that reported by Assiri [12], as well as to that reported in most patients presenting to the emergency department with IE [17], however, fever was reported slightly less by Zaqout et al. in Qatar (84\%). Only one-fifth of our patients had a documented audible murmur which is much lower than a study by Yakut et al. that reported a new murmur or changing murmur in $68 \%$ of patients [18]. Previous studies from KSA and Qatar did not report the number of murmurs in their cases. Splenomegaly with or without hepatomegaly was documented in $5.5 \%$ of our patients, detecting splenomegaly during assessment of patients with suspected IE is important, Rohani et al. reported a case of IE presenting with isolated splenomegaly [19]. Systemic embolization and/or stroke was observed in almost $7 \%$ of our patients, which is similar to that reported by Zaqout et al., while Assiri reported stroke in $9 \%$ of patients and another $4.5 \%$ developed peripheral septic emboli. A study from Spain reported embolic events in almost $12 \%$, mostly affecting the central nervous system [20]. Sixty-seven or $20 \%$ of our study population developed acute kidney injury that required renal replacement therapy, the study from Qatar reported acute kidney injury in 30\%, while that from Aseer reported renal failure in $4.5 \%$, both studies did not report the requirement of renal replacement therapy. A French hospital discharge database on 112 patients with IE showed that $27 \%$ developed stage 3 acute kidney injury, while only three patients required renal replacement therapy [21].

In certain clinical situations, a combined medical and surgical approach is necessary for the successful treatment of IE. During the last three decades, valve replacement and repair have become common practice in the management of selected complications of IE, and the combination of antibiotic therapy and timely surgical intervention has substantially reduced the mortality from IE. Our results demonstrate that $26 \%$ of IE cases required surgical intervention, which, like other reports, showed it to be between 25 and $50 \%$ during acute infection and 20-40\% during convalescence [22-24]. The previous report from Aseer showed that $50 \%$ of patients underwent surgery [12], while only $16 \%$ of those in Qatar required surgical intervention [13]. Over time, the indications for surgery have been extended and valve replacement surgery has been undertaken progressively earlier in the course of the illness. The indications for surgery in our patients were consistent with the guidelines of the American College of Cardiology/American Heart Association, namely congestive heart failure, systemic embolic events, valve dysfunction, failure of medical therapy and perivalvular complications such as abscess formation and large mobile vegetation.

After prosthetic valves, rheumatic heart disease was the most common risk factor of IE in our study, Assiri also reported it to be the highest risk factor among 44 patients [12]. The third most common predisposing factor for IE was congenital heart disease reported in almost one-tenth of our study population, which is much higher than that reported in Qatar [13]. Interestingly, Coxiella burnetii, the causative agent of Q-fever, was common in in our congenital heart disease cohort, this can be explained in part by cardiac implants, bovine jugular transplants and the endemicity of Q-fever in some regions of Saudi Arabia [25].

The number of native valve IE and prosthetic valve IE were $111(32.6 \%)$ and $109(32 \%)$, respectively, which is nearly equal, one explanation would be the referral of complicated prosthetic valve cases from other hospitals around the whole Kingdom, causing higher reports from developed countries for prosthetic valve IE, the previous report from the Eastern region showed that only $18.5 \%$ were prosthetic 
valve IE [8], and the study from Aseer region reported it to be $22.7 \%$ [12], while the study from Qatar reported it to be $19 \%$ [13].

The yield of microorganisms isolated from blood cultures $(52.05 \%)$ was closer to a study by Ghosh from North India [26]. Low yield could be due to prior use of antibiotics before cultures were withdrawn and referred patients may have already been on treatment that was started in the original referring hospitals. Staphylococcus spp endocarditis was predominantly reported in this study which agrees with several reports from developed countries [27], as we found that MSSA caused 24 and 22\% of culture-positive native and prosthetic valve endocarditis, respectively, while MRSA caused almost $8 \%$ of both native and prosthetic valve IE. Overall, the most frequent isolate in prosthetic valve IE was coagulase negative staphylococcus (CONS) (32.1\%), Al-Tawfiq et al. similarly reported staphylococcus spp as the most common microorganism with staphylococcus aureus in nearly $40 \%$, MRSA in 4\%, CONS in 7.4\% [8], while Assiri reported staphylococcus aureus in $18.2 \%$ and CONS in $4.5 \%$. In Qatar, MSSA, MRSA, CONS were reported to be $14,11,9 \%$, respectively. In our study Viridans group streptococci caused 31.5 and $10.3 \%$ of native and prosthetic valve IE, respectively, both Assiri and Zaquot et al. reported it to cause $14 \%[12,13]$, while Al-Tawfiq et al. reported it to cause $17 \%$ [8], none of these studies segregated their microbiology data into native or prosthetic valve IE.

Antimicrobial resistance was noticeable in 28 bacterial isolates (16.3\%) out of which $22(78.5 \%)$ were gram positive organisms and $6(21.4 \%)$ were gram negative organisms, In Eastern region $9 \%$ were gram negative bacteria, of which one case was due to ESBL-producing klebsiella pneumoniae [8], similarly we report five and one cases of MDR and XDR klebsiella pneumoniae, respectively.

Over the last 20 years echocardiography has complimentary roles in the diagnosis and evaluation of endocarditis. The sensitivity of TTE in this study was $63.6 \%$ which was lower than that reported by Al-Tawfiq et al. at 72\% [8], the low negative predictive value confirms that TEE would be essential to diagnose IE when TTE is Inconclusive [28].

A large body of evidence has shown that aortic valves have replaced mitral valves as the most common infected site in IE. However, we observed a predominance of mitral valve infection [29]. Similarly, all previous studies from the region reported predominance of mitral valve involvement $[8,12,13]$. Our data also indicates that $27 \%$ of patients had complications which have been previously reported [22]. In-hospital mortality was $6.76 \%$, which is lower than what is reported in most case series of 24\% [30]. The mortality rate of our cases due to Staphylococcus aureus endocarditis $11(47.82 \%)$ is inconsistent with other reports with mortalities of $25 \%$ [31, 32]. Numerous studies had previously reported a wide range of in-hospital mortality between 15 and 31\% [30, 33-39], in Qatar the mortality was 25\% [13], and the study from Eastern KSA reported a mortality rate of $29.4 \%$ [8].

Although the present study evaluates a large number of IE cases over a five-year period with scarce studies in KSA [12], it has many limitations including it focusing on a single cardiac center with possible influence of referral bias, it is a retrospective study with few missing data including treatment duration, as well as long term follow-up, however, this is the first study from a major cardiac center (PSCC) that serves as a referral center for all KSA, hence, the descriptive epidemiological data may reflect most cases within the country, in addition, this is the largest case series of IE reported in the region, with various predisposing factors including rheumatic and congenital heart diseases, and the most diverse detailed microbiology data from KSA.

\section{Conclusion}

Over a five-year period in the largest cardiac center in KSA, 340 patients were diagnosed with infective endocarditis, fever was the most common presenting symptom, one-third of all cases had prosthetic valve endocarditis, and rheumatic and congenital heart diseases were the most common predisposing factors. A wide variety of causative microorganisms were identified with majority of cases caused by staphylococci spp. and streptococci spp. while MDR and XDR gram-negative bacteria were rare. Culture negative endocarditis was mostly caused by Q-fever and brucellosis. Surgical intervention was done in one-quarter of all patients. The overall in-hospital mortality was low. Prospective multicenter studies in KSA to validate and expand on these results are warranted.

Author Contributions MB conceived and designed the study, conducted research, provided research materials, and collected and organized data, SAB analyzed and interpreted data, MYA wrote initial and final draft of article, and provided logistic support, FN wrote initial and final draft of article, and provided logistic support, RE wrote initial and final draft of article, and provided logistic support, $\mathrm{AK}$ and $\mathrm{YH}$ wrote initial and final draft of article, and provided logistic support. All authors have critically reviewed and approved the final draft and are responsible for the content and similarity index of the manuscript.

Funding This research did not receive any specific grant from funding agencies in the public, commercial, or not for- profit sectors.

Availability of Data and Material All data are available upon reasonable request to corresponding author.

\section{Declarations}

Conflict of Interest There are no financial or personal considerations which may have compromised the study or created bias in conducting and reporting the study findings. 
Ethical Approval The study was reviewed and approved by the Prince Sultan cardiac center ethics committee board with research file number R20012.

Consent to Participate Informed consent was obtained from all individual participants included in the study.

Open Access This article is licensed under a Creative Commons Attribution 4.0 International License, which permits use, sharing, adaptation, distribution and reproduction in any medium or format, as long as you give appropriate credit to the original author(s) and the source, provide a link to the Creative Commons licence, and indicate if changes were made. The images or other third party material in this article are included in the article's Creative Commons licence, unless indicated otherwise in a credit line to the material. If material is not included in the article's Creative Commons licence and your intended use is not permitted by statutory regulation or exceeds the permitted use, you will need to obtain permission directly from the copyright holder. To view a copy of this licence, visit http://creativecommons.org/licenses/by/4.0/.

\section{References}

1. Capilla E, Poyet R, Tortat AV, Marchi J, Brocq FX, Kerebel $\mathrm{PF}$, et al. Infective endocarditis: clinical features and prognosis between 2004 and 2014 in a non-teaching hospital. Ann Cardiol Angeiol. 2017;66:87-91. https://doi.org/10.1016/j.ancard.2016. 09.042 (PMID: 28093099).

2. Nashmi A, Memish ZA. Infective endocarditis at a tertiary care centre in Saudi Arabia: review of 47 cases over 10 years. East Mediterr Health J. 2007;13(1):64-71.

3. Cahill TJ, Baddour LM, Habib G, Hoen B, Salaun E, Pettersson $\mathrm{GB}$, et al. Challenges in infective endocarditis. J Am College Cardiol. 2017;69:325-44. https://doi.org/10.1016/j.jacc.2016.10.066.

4. Cresti A, Chiavarelli M, Scalese M, Nencioni C, Valentini S, Guerrini F, et al. Epidemiological and mortality trends in infective endocarditis, a 17-year population-based prospective study. J Cardiovasc Diagn Ther. 2017. https://doi.org/10.21037/cdt.2016. 08.09 and Osler W. Gulstonian lectures on malignant endocarditis. Lancet 1885;1:415-8.

5. Habib G, Lancellotti P, Antunes MJ, Bongiorni MG, Casalta JP, Del Zotti F, et al. ESC Guidelines for the management of infective endocarditis. Eur Heart J. 2015;2015(36):3075-128.

6. Iung B, Duval X. Infective endocarditis: innovations in the management of an old disease. Nat Rev Cardiol. 2019;16(10):623-35. https://doi.org/10.1038/s41569-019-0215-0 (PMID: 31175343).

7. Fedeli U, Schievano E, Buonfrate D, Pellizzer G, Paolo S. Increasing incidence and mortality of infective endocarditis: a population-based study through a record-linkage system. BMC Infect Dis. 2011;11:48.

8. Al-Tawfiq JA, Sufi I. Infective endocarditis at a hospital in Saudi Arabia: epidemiology, bacterial pathogens and outcome. Ann Saudi Med. 2009;29(6):433-6. https://doi.org/10.4103/02564947.57164.

9. Khan O, Shafi AMA. Timmis AInternational guideline changes and the incidence of infective endocarditis: a systematic review. Open Heart. 2016;3: e000498. https://doi.org/10.1136/openh rt-2016-000498.

10. Vincent LL, Otto CM. Infective endocarditis: update on epidemiology, outcomes, and management. Curr Cardiol Rep. 2018;20(10):86. https://doi.org/10.1007/s11886-018-1043-2.

11. Zahedib FI, Kurupc PJ, Al-Jardanid AK, Beeching NJ, et al. The epidemiology and outcomes of infective endocarditis in a tertiary care hospital in Muscat, Oman. J Infect Public Health. 2014;7:400-6.

12. Assiri AS. Clinical and microbiological profiles of infective endocarditis in a tertiary hospital in Aseer region, Saudi Arabia. J Saudi Heart Assoc. 2011;23:207-11.

13. Zaqout A, Mohammed S, Thapur M, Al-Soub H, Al-Maslamani MA, Al-Khal A, Omrani AS. Clinical characteristics, microbiology, and outcomes of infective endocarditis in Qatar. Qatar Med J. 2020;2020(2):24. https://doi.org/10.5339/qmj.2020.24.PMID: $33282709 ;$ PMCID:PMC7684547.

14. Vallejo FAG. Epidemiology of infective endocarditis. Intech Open Sci J. 2016. https://doi.org/10.5772/65030.

15. He VYF, Condon JR, Ralph AP, Zhao Y, Roberts K, et al. Longterm outcomes from acute rheumatic fever and rheumatic heart disease. Circulation. 2016;134:222-32.

16. Sika-Paotonu D, Beaton A, Raghu A, Steer A, Carapetis J, Acute rheumatic fever and rheumatic heart disease 2017 Mar 10 [updated 2017 Apr 3]. In: Ferretti JJ, Stevens DL, Fischetti VA, editors. Streptococcus pyogenes: basic biology to clinical manifestations. Oklahoma City: University of Oklahoma Health Sciences Center; 2016.

17. Long B, Koyfman A. Infectious endocarditis: an update for emergency clinicians. Am J Emerg Med. 2018;36(9):1686-92. https:// doi.org/10.1016/j.ajem.2018.06.074 (Epub 2018 Jul 2 PMID: 30001813).

18. Yakut K, Ecevit Z, Tokel NK, Varan B, Ozkan M. Infective endocarditis in childhood: a single-center experience of 18 years. Braz J Cardiovasc Surg. 2021;36(2):172-82. https://doi.org/10.21470/ 1678-9741-2020-0035.PMID:33113327;PMCID:PMC8163273.

19. Rohani A, Akbari V, Homayoon K. Infective endocarditis presents as isolated splenomegaly. J Cardiovasc Dis Res. 2011;2(1):71-3. https://doi.org/10.4103/0975-3583.78601.PMID:21716757; PMCID:PMC3120277.

20. Vilacosta I, Graupner C, San Román JA, Sarriá C, Ronderos R, Fernández C, Mancini L, Sanz O, Sanmartín JV, Stoermann W. Risk of embolization after institution of antibiotic therapy for infective endocarditis. J Am Coll Cardiol. 2002;39(9):1489_ 95. https://doi.org/10.1016/s0735-1097(02)01790-4 (PMID: 11985912).

21. Gagneux-Brunon A, Pouvaret A, Maillard N, Berthelot P, Lutz MF, Cazorla C, Tulane C, Fuzellier JF, Verhoeven PO, Frésard A, Duval X, Lucht F, Botelho-Nevers E. Acute kidney injury in infective endocarditis: A retrospective analysis. Med Mal Infect. 2019;49(7):527-33. https://doi.org/10.1016/j.medmal.2019.03. 015. (Epub 2019 Apr 4 PMID: 30955847).

22. Prendergast BD, Tornos P. Surgery for infective endocarditis. Circulation. 2010;121:1141-52.

23. Baddour LM, Wilson WR, Bayer AS, Fowler VG Jr, Tleyjeh IM, Rybak MJ. Infective endocarditis in adults: diagnosis, antimicrobial therapy, and management of complications: a scientific statement for healthcare professionals from the American Heart Association. Circulation. 2015;132(15):1435-86. https://doi.org/ 10.1161/CIR.0000000000000296.

24. Pettersson GB, Coselli JS, Hussain ST, Griffin B, Blackstone $\mathrm{EH}$, Gordon SM, et al. AATS surgical treatment of infective endocarditis consensus guidelines. J Thorac Cardiovasc Surg. 2017;153(6):1241-58. https://doi.org/10.1016/j.jtcvs.2016.09. 093.

25. Elzein FE, Alsherbeeni N, Alnajashi K, Alsufyani E, Akhtar MY, Albalawi R, et al. Ten-year experience of Q fever endoacarditis in a tertiary cardiac centre in Saudi Arabia. Int J Infect Dis. 2019. https://doi.org/10.1016/j.ijid.2019.07.035.

26. Ghosh S, Sahoo R, Nath RK, Duggal N, Gadpayle AK. Study of clinical, microbiological, and echocardiographic profile of patients of infective endocarditis. Int Scholarly Res Notices. 2014. https://doi.org/10.1155/2014/340601. 
27. Holland TL, Baddour LM, Bayer AS, Hoen B, Miro JM, Fowler VG Jr, et al. Infective endocarditis. Nature Rev. 2016. https://doi. org/10.1038/nrdp.2016.59.

28. Lyons K, Bhamidipati K. Comparison of transthoracic and transoesophageal echocardiography in the diagnosis of infective endocarditis-a tertiary centre experience. BMJ Heart. 2017. https:// doi.org/10.1136/heartjnl-2017-ICS17.4.

29. Brusch JL, Bronze MS. Harvard Medical School Infective Endocarditis Department of Medicine and Infectious Disease Service, Cambridge Health Alliance. 2019. https://emedicine.medscape. com/article/216650-treatment.

30. Cresti A, Chiavarelli M, Scalese M, Nencioni C, Valentini S, Guerrini F, et al. Epidemiological and mortality trends in infective endocarditis, a 17-year population-based prospective study. Cardiovasc Diagn Ther. 2017;7(1):27-35.

31. Broa AL, Joao I, Pereira H. Risk factors for in-hospital mortality in infective endocarditis. Arq Bras Cardiol. 2019. https://doi.org/ 10.36660/abc. 20180194.

32. Gudiol F, Aguado JM, Almirante B, Bouza E, Cercenado E, Domínguez MÁ, et al. Diagnosis and treatment of bacteremia and endocarditis due to Staphylococcus aureus A clinical guideline from the Spanish Society of Clinical Microbiology and Infectious Diseases (SEIMC). Enferm Infecc Microbiol Clin. 2015. https:// doi.org/10.1016/j.eimc.2015.03.015.

33. Krajinovic V, Ivancic S, Gezman P, Barsic B. Association between cardiac surgery and mortality among patients with infective endocarditis complicated by sepsis and septic shock. Shock. 2018;49(5):536-42.
34. Leone S, Ravasio V, Durante-Mangoni E, Crapis M, Carosi G, Scotton PG, et al. Epidemiology, characteristics, and outcome of infective endocarditis in Italy: the Italian Study on Endocarditis. Infection. 2012;40(5):527-35.

35. Olmos C, Vilacosta I, Fernandez C, Lopez J, Sarria C, Ferrera C, et al. Contemporary epidemiology and prognosis of septic shock in infective endocarditis. Eur Heart J. 2013;34(26):1999-2006.

36. Garcia-Cabrera E, Fernandez-Hidalgo N, Almirante B, IvanovaGeorgieva R, Noureddine M, Plata A, et al. Neurological complications of infective endocarditis: risk factors, outcome, and impact of cardiac surgery: a multicenter observational study. Circulation. 2013;127(23):2272-84.

37. Ferreira JP, Gomes F, Rodrigues P, Abreu MA, Maia JM, Bettencourt P, et al. Left-sided infective endocarditis: analysis of inhospital and medium-term outcome and predictors of mortality. Rev Port Cardiol. 2013;32(10):777-84.

38. Murdoch DR, Corey GR, Hoen B, Miró JM, Fowler VG Jr, Bayer AS, et al. Clinical presentation, etiology, and outcome of infective endocarditis in the 21st century: The International Collaboration on Endocarditis-Prospective Cohort Study. Arch Intern Med. 2009;169(5):463-73.

39. Marques A, Cruz I, Caldeira D, Alegria S, Gomes AC, Broa AL, João I, Pereira H. Risk factors for in-hospital mortality in infective endocarditis. Arq Bras Cardiol. 2020;114(1):1-8. https://doi.org/ 10.36660/abc.20180194.PMID:31751437;PMCID:PMC7025303. 